\title{
EFCOG Best Practice Submission - Guidance for Retro-Commissioning
}

\author{
Ernest L. Fossum
}

January 2006

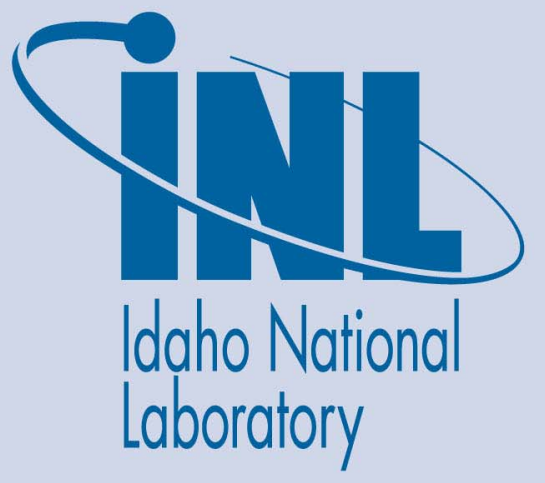

The INL is a U.S. Department of Energy National Laboratory operated by Battelle Energy Alliance 
INL/EXT-06-01090

\title{
EFCOG Best Practice Submission - Guidance for Retro-Commissioning
}

\author{
Ernest L. Fossum
}

January 2006

\begin{abstract}
Idaho National Laboratory
Idaho Falls, Idaho 83415
\end{abstract}

Prepared for the

U.S. Department of Energy

Office of Nuclear Energy

Under DOE Idaho Operations Office

Contract DE-AC07-05ID14517 


\begin{abstract}
Commissioning is slowly becoming an accepted quality method for ensuring that buildings are designed, constructed, and operated as required by the building owner and as intended by the original design.

Retro-commissioning is a process, using commissioning concepts, to ensure that existing buildings are operated and maintained as required by the owner to meet the building's current mission. Retro-commissioning further seeks to incorporate new equipment and operating practices to upgrade existing facilities to obtain increased efficiency and employee comfort and productivity.

Retro-commissioning practices are not universal. Best practices have been identified to assist Federal organizations with the development of retrocommissioning programs and to help DOE sites to begin this quality related process.
\end{abstract}




\section{SUMMARY}

This report describes the research and development for an EFCOG Energy Efficiency Working Group Best Practice, the Guidance for Retro-commissioning.

Commissioning is the term applied to the systematic process of ensuring that a building is designed, constructed, and operated according the owner's defined design and operational requirements.

Retro-commissioning ( $\mathrm{RCx}$ ), sometimes called "Existing Building Commissioning", is the term applied to the evaluation of an existing building for correct operations, tenant comfort, energy efficiency, and for compliance to the building owners original design and operational requirements. $\mathrm{RCx}$ is often further applied to determine additional adjustments, modifications, or improvements that will increase the building's reliability, tenant comfort and productivity, and overall energy efficiency.

The Federal government is adopting commissioning in the Federal sector as a quality method of ensuring that buildings work as designed and needed. As many Federal buildings have never had any form of Commissioning applied during or after construction, the Federal government is seeking to apply retro-commissioning as a method to ensure that these existing buildings are operated as efficiently as possible and in a manner conducive to high tenant comfort and productivity.

This guidance contains best practices, identified through research of commissioning concepts and through experience applying the commissioning process at several DOE laboratories. These best practices will assist with the development of RCx programs at DOE sites in particular and are arranged in the following focus areas:

Focus Area 1 What is RCx?

Focus Area 2 When should RCx be Implemented?

Focus Area 3 Goals of the RCx Process

Focus Area 4 Obtaining Management Support

Focus Area 5 Setting up the RCx Team

Focus Area 6 Performing the RCx Process

Focus Area 7 Maintaining the RCx Program

Focus Area 8 RCx References

All DOE sites and Federal entities are welcome to adapt all or portions of this guidance into site-specific operational standards with the goal of a sustainable commissioning program for existing buildings that will provide DOE with the best facilities possible.

These best practices were prepared for the Departmental Energy Management Program (DEMP) through a Model Program funding grant. Total funding used for this project was $\$ 27,599$. The deliverable was presented at the Energy Efficiency Working Group (EEWG) meeting on August 18, 2005 and was submitted for posting on the Energy Facility Contractors Group (EFCOG) Best Practices website. 


\section{ACKNOWLEDGMENTS}

Funding for this Best Practices development was provided by the DOE Departmental Energy management Program to perform the primary legwork and coordination with the other DOE sites and was greatly appreciated. This project was the vision of Will Lintner of the Departmental Energy Management Program (DEMP).

I would like to acknowledge those who took time to provide best practices input, retro-commissioning data and information, and review of the guidance and report. Nick Malik, Blair Horst, Mike Moran, Chris Evans, and Dale Sartor were especially helpful.

Ernest L. Fossum, CEM 


\section{CONTENTS}

ABSTRACT

SUMMARY . $\mathrm{V}$

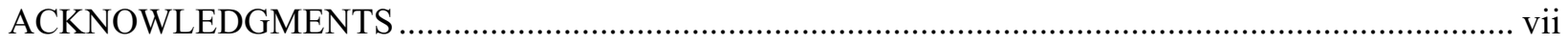

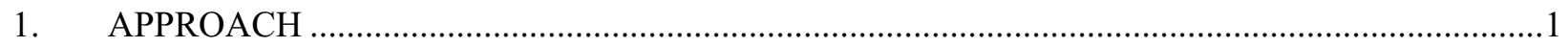

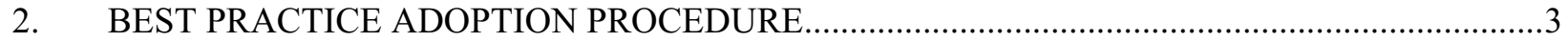

3. APPLICATION FOR EFCOG BEST PRACTICE CONSIDERATION …...................................

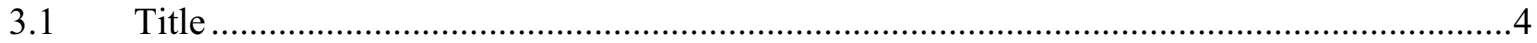

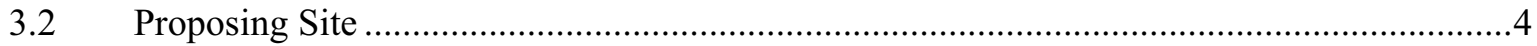

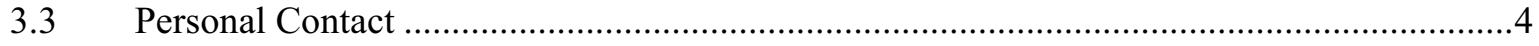

3.4 Relationship to Integrated Safety Management Core Function and Guiding Principles

3.5 Attributes of the Candidate Best Practice ........................................................................

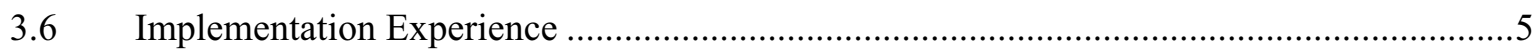

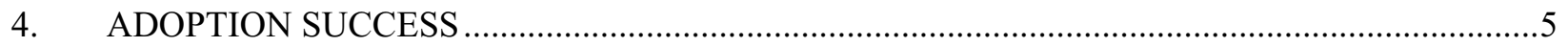

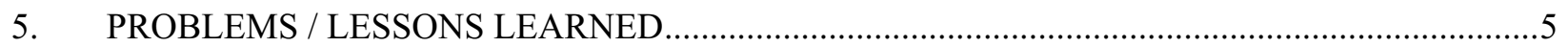

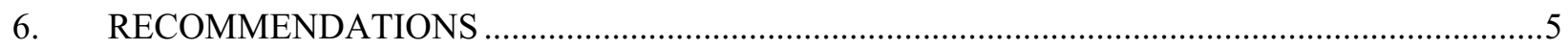

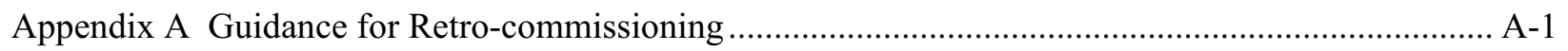

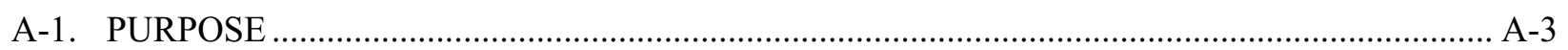

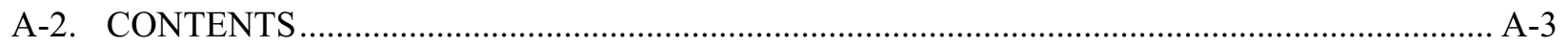

A-3. Commissioning Definitions / Terminology ….............................................................................. A-3

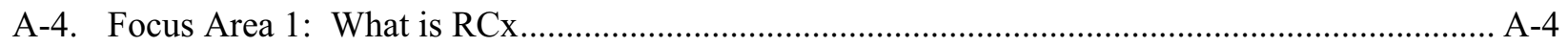

A-5. Focus Area 2: When Should RCx be Implemented ................................................................ A-4

A-6. Focus Area 3: Goals of the RCx Process ................................................................................... A-6

A-7. Focus Area 4: Obtaining Management Support ........................................................................ A-6

A-8. Focus Area 5: Setting Up the RCx Team .................................................................................. A-7

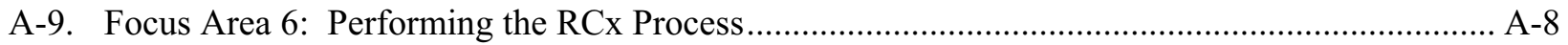


A-10. Focus Area 7: Maintaining the RCx Program.

A-10

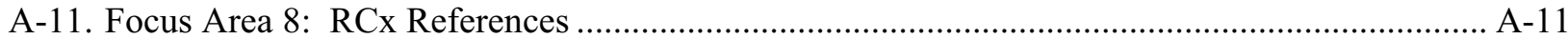

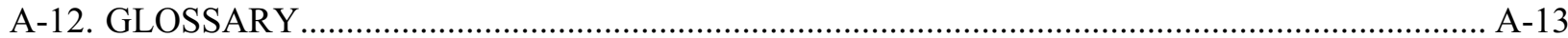




\section{EFCOG Best Practice Submission - Guidance for Retro-commissioning}

\section{APPROACH}

Commissioning is the term applied to the systematic process of ensuring that a building is designed, constructed, and operated according the owner's defined design and operational requirements.

Retro-commissioning ( $\mathrm{RCx}$ ), sometimes called "Existing Building Commissioning", is the term applied to the evaluation of an existing building for correct operations, tenant comfort, energy efficiency, and for compliance to the building owners original design and operational requirements. RCx is often further applied to determine additional adjustments, modifications, or improvements that will increase the building's reliability, tenant comfort and productivity, and overall energy efficiency.

The Federal government is adopting commissioning in the Federal sector as a quality method of ensuring that buildings work as designed and needed. As many Federal buildings have never had any form of commissioning applied during or after construction, the Federal government is seeking to apply retro-commissioning as a method to ensure that these existing buildings are operated as efficiently as possible and in a manner conducive to high tenant comfort and productivity.

This EFCOG Best Practice submission includes an appendix with guidance on best practices, identified through research of commissioning concepts and through experience applying the commissioning process at several DOE laboratories. These best practices will assist with the development of RCx programs at DOE sites in particular and are arranged in the following focus areas:

Focus Area 1 What is $\mathrm{RCx}$ ?

Focus Area 2 When should RCx be Implemented?

Focus Area 3 Goals of the RCx Process

Focus Area 4 Obtaining Management Support

Focus Area 5 Setting up the RCx Team

Focus Area 6 Performing the RCx Process

Focus Area 7 Maintaining the RCx Program

Focus Area 8 RCx References

The Guidance for Retro-commissioning, included as an Appendix, consists of recommendations for retro-commissioning intended for incorporation into individual DOE site Retro-commissioning programs, either to assist with initial development or to enhance existing functioning programs. The purpose of the Guidance is to provide DOE sites with suggested actions that need to occur while developing and implementing retro-commissioning programs and may be used unconditionally as needed or modified to reflect individual site operational needs.

The guidance was developed from the review of documentation from research and reports on commissioning principles, successful retro-commissioning activities at DOE sites, documentation from retro-commissioning training programs, and through suggestions from the following participating DOE sites: 
Sandia National Laboratory

Lawrence Berkeley Laboratory

Argonne National Laboratory

Pacific Northwest National Laboratory

National Renewable Energy Laboratory

Idaho National Laboratory

Various source materials and references were used to develop and prepare these Retrocommissioning Best Practices. These sources and/or references include:

1. Training Guide for The Commissioning Process for Retro-Commissioning Projects, Charles Dorgan, Program Director, Department of Engineering Professional Development, University of Wisconsin - Madison, January 27-28, 2005

Note: The Training Guide was used only for informational purposes. The University of Wisconsin - Madison, Department of Engineering Professional Development, has not endorsed this Best Practices document and has not collaborated with its development.

2. A Practical Guide for Commissioning Existing Buildings, Tudi Haasl, Portland Energy Conservation, Inc., Terry Sharp, Oak Ridge National Laboratory, April 1999.

3. The Cost-Effectiveness of Commercial-Buildings Commissioning, Mills, Friedman, Powell, Bourassa, Claridge, Haasl, and Piette - Lawrence Berkeley National Laboratory, Portland Energy Conservation Inc., Energy Systems Laboratory: Texas A\&M University, December 15, 2004.

4. Departmental Energy and Utilities Management, DOE Order 430.2A, US Department of Energy, April 15, 2002.

5. FEMP Continuous Commissioning Guidebook for Federal Energy Mangers by Texas A\&M University, October 2002, available through http://ateam.lbl.gov/mv.

6. Building Commissioning Handbook, Heinz, John, P.E., APA Publications, Alexandrea, VA, 1996

Please note that this Guidance report is not intended to identify all aspects of retro-commissioning or even to identify all best practices related to retro-commissioning. Retro-commissioning is an emerging quality assurance process that is likely to change as new ideas and methods are either developed or improved upon over time.

This Guidance is intended to assist DOE sites to get started setting up an on-going retrocommissioning program with the best information available to date. Sites should use the guidance in any manner that will expedite setting up a program and begin the process of making Federal and leased buildings more efficient, comfortable, and productive. 


\section{BEST PRACTICE ADOPTION PROCEDURE}

The Guidance for Retro-commissioning Best Practice must meet the following criteria to be considered for posting on the EFCOG website:

1. Practice is proven through successful implementation and use.

2. Practice has broad applicability across the Complex as opposed to being more specific to one site.

3. Conditions needed for adoption by others are adequately defined.

4. Benefits and value are clearly and quantitatively defined.

5. Cost and resource expectations for adoption are sufficiently defined.

6. Proposing site has senior management support to share the Best Practice and is willing to mentor adopters.

7. Recommended implementation scenario and support structure are properly defined.

8. Best Practice is categorized in one or more of the Integrated Safety Management Core Functions and Guiding Principles.

The Best Practices Guidance for Retro-commissioning meets all the above criteria. As a compilation of processes currently or recently used at one or more of six DOE sites, the practices are proven and have broad applicability across the Complex. As discussed above, sites may choose to adopt all or some of the process recommendations, and may reword for necessary strength and local applicability.

The benefit and value of retro-commissioning is clearly discussed in the recent publication, The Cost-Effectiveness of Commercial-Buildings Commissioning, A Meta-Analysis of Energy and Non-Energy Impacts in Existing Buildings and New Construction in the United States, sponsored by the Assistant Secretary for Energy Efficiency and Renewable Energy (EERE) and published in December 2004.

Note: An electronic copy of this document and data input forms are available at:

$$
\text { http://eetd.lbl.gov/emills/PUBS/Cx-Costs-Benefits.html }
$$

The proposing site, the INL, has senior management support for sharing the Guidance as a Best Practice as evidenced by approval for external release and submission to EFCOG. INL will also provide mentoring for adopters should such a support structure be needed.

Finally, the Guidance for Retro-commissioning Best Practice can be categorized in the ISM Core Functions and Guiding Principles as explained in the Application for Best Practice Consideration.

An application for EFCOG Best Practice Consideration was developed and submitted to the approving committee in January of 2006. 


\section{APPLICATION FOR EFCOG BEST PRACTICE CONSIDERATION}

\subsection{Title}

Guidance for Retro-commissioning

\subsection{Proposing Site}

Idaho National Laboratory (INL)

\subsection{Personal Contact}

Ernest L. Fossum, CEM, LEED Accredited Professional

Engineering Services, Facilities \& Site Services Department

Email: Ernest.Fossum@inl.gov

Phone (208) 526-2513

\subsection{Relationship to Integrated Safety Management Core Function and Guiding Principles}

The Guidance for Retro-commissioning relates closely to Integrated Safety Management Guiding Principles 3, 4, and 7: Competence Commensurate with Responsibilities, Balanced Priorities, and Operations Authorization.

As retro-commissioning is a quality driven process requiring trained personnel to head an implementation team, and all personnel participating on the team to be educated on the process and be leaders in their respective areas of expertise, the guidance document helps to ensure that the best and most knowledgeable personnel participate in a process that results in more efficient, healthy, and productive facilities affecting many personnel from varying disciplines.

As stated, retro-commissioning is a quality driven process, which helps sites to balance the priorities of operational costs, employee health and safety, and environmental stewardship. Many of the results of retro-commissioning lead to improved employee comfort and health, which implies improved research productivity and lower costs. Other results of retro-commissioning lead to increased energy and water conservation, which implies less impact on the local and global environment and lower operating costs.

Finally, retro-commissioning primarily leads to correct operations in Federal facilities, which results in clear and concise operating instructions and responsibilities.

\subsection{Attributes of the Candidate Best Practice}

The Guidance for Retro-commissioning provides suggestions for successful development and incorporation of commissioning activities in existing Federal facilities. These guidelines have been recommended through research on commissioning practices and through their implementation at various DOE sites. The purpose of this guidance is to provide high level, adaptable recommendations that will enhance retro-commissioning processes used at DOE sites. 
The Guidance for Retro-commissioning can be viewed as a checklist and contains numerous recommendations that should become normal practice. However, DOE sites are welcome to adapt all or portions of the entries into site-specific operational standards with the goal of a sustainable commissioning program for existing buildings that will provide DOE with the best facilities possible.

\subsection{Implementation Experience}

Several DOE sites have experience implementing RCx and individuals associated with that implementation have contributed to this Best Practices submission. DOE sites with experience include:

Argonne National Laboratory

Idaho National Laboratory

Lawrence Berkeley Laboratory

National Renewable Energy Laboratory

Pacific Northwest National Laboratory

Sandia National Laboratory

\section{ADOPTION SUCCESS}

In January 2006, the Guidance for Retro-commissioning was forwarded to the Energy Facility Contractors' Group (EFCOG) Best Practices approval committee as a deliverable. The Guidance is now posted as an EFCOG Best Practice under the Energy Efficiency category at: http://www.efcog.org/.

\section{PROBLEMS / LESSONS LEARNED}

The primary problem of assembling best practices for retro-commissioning is the variability of the definitions and implementation strategy for commissioning in general and more specifically retrocommissioning. Efforts were made to define retro-commissioning for this EFCOG Best Practice using the best of the available concepts and strategies to facilitate retro-commissioning in a manner that can be implemented without excessive costs at most DOE sites.

The preparation of this document was facilities through a team approach among DOE Laboratories that have experience implementing RCx. Like other EFCOG Best Practices, this document is intended to be a living document and should be subject to periodic recommendations and updates when it is used or as the concepts evolve.

\section{RECOMMENDATIONS}

The concepts outlined in the Appendix should be implemented across the DOE complex as needed for individual sites to develop or enhance RCx programs. Future EFCOG Best Practices should be developed using a team and consensus approach. 


\section{Appendix A}

\section{Guidance for Retro-commissioning}




$$
\text { A-2 }
$$




\section{Appendix A}

\section{Guidance for Retro-commissioning}

\section{A-1. PURPOSE}

The following guidance consists of recommendations that will assist with the development and incorporation of a retro-commissioning process or program. The purpose of this guidance is to provide high level information that can be tailored to meet the needs of individual retro-commissioning programs being developed or enhanced at DOE sites.

DOE sites are encouraged to adapt all or portions of the recommendations into site-specific retrocommissioning programs.

\section{A-2. CONTENTS}

This guidance contains information and recommendations on the following topics organized in the sequential manner in which they should be addressed:

Commissioning Definitions / Terminology

Focus Area 1 What is $\mathrm{RCx}$

Focus Area 2 When should RCx be Implemented

Focus Area 3 Goals of the RCx Process

Focus Area 4 Obtaining Management Support

Focus Area 5 Setting up the RCx Team

Focus Area 6 Performing the RCx Process

Focus Area 7 Maintaining the RCx Program

Focus Area 8 RCx References

Glossary

\section{A-3. Commissioning Definitions / Terminology}

a. Commissioning is essentially a systematic quality related process for ensuring that the performance of facilities and systems meet defined criteria and efficiency objectives set by owners, tenants, and other stakeholders.

b. Commissioning is ideally implemented at the beginning of the design development phase and continues through initial occupancy and beyond. 
c. Re-commissioning is performed several years after a building, that was previously commissioned, has been in operation to ensure that the building and systems are meeting the original design requirements. Re-commissioning is typically used to identify and correct malfunctions in a building that occur as the building ages and to ensure continued indoor air quality, employee productivity, and energy efficiency.

d. Re-commissioning can also be used to address changes in ownership, building use patterns, and operation and maintenance practices. A building's use and mission often change during the building's life and these changes necessitate the need for re-commissioning to ensure that the building is capable of efficiently meeting its new and/or evolving mission.

e. Continuous commissioning involves ongoing monitoring and testing of systems as part of a regular maintenance plan to ensure continued optimum performance and enhanced equipment longevity. Continuous commissioning can be applied to individual systems or the entire building depending upon the requirements of the stakeholders.

\section{A-4. Focus Area 1: What is RCx}

a. Retro-commissioning $(\mathrm{RCx})$ involves applying the commissioning process to a building that has never been commissioned. Retro-commissioning is sometimes referred to as "Existing Building Commissioning".

b. RCx uses the commissioning process to compare the building's original design parameters and operational criteria with current design and operational requirements. $\mathrm{RCx}$ then determines whether the building is capable of meeting the current design and operational criteria as a minimum.

c. RCx then identifies the required system modifications necessitated by the building's mission changes in order to meet its current operational and tenant needs.

d. RCx should then identify upgrades to the building that will enhance its energy efficiency, tenant comfort and productivity, and indoor air quality. These upgrades often incorporate state-of-theart equipment and systems needed to improve the efficiency and operational effectiveness of the building. RCx often enhances property value.

e. RCx has differing meanings to various groups and interests. For the purpose of this document, $\mathrm{RCx}$ as a best Practice means using a whole building approach to ensure that the building and systems are operating within well-defined criteria established by the building stakeholders. The emphasis is on "defined operational needs" and "whole building approach".

f. The benefits of RCx often include lower operation and maintenance costs, lower utility costs, reduced repairs and system downtime, increase occupant comfort, increased productivity, improved indoor air quality, and enhanced skill of operations and maintenance staff.

\section{A-5. Focus Area 2: When Should RCx be Implemented}

a. Whenever significant changes occur in building occupancy, space utilization, equipment configuration, or maintenance practices. The RCx process should be used as a tool to identify and document the new operational requirements and to provide a formal method for accomplishing the required modifications to meet the new operational criteria. 
b. Whenever sections of buildings and systems are undergoing a significant upgrade. The $\mathrm{RCx}$ process can also be applied simultaneously to other portions of the building that are not directly affected by the upgrade. Ensuring that the existing systems are working properly and efficiently will maximize the chances that the new upgrade will meet design criteria and performance requirements as set by the stakeholders.

c. When energy-use trending reveals an increase over time, which may be attributed to control drift or equipment wear. A distinct shift in energy use that may be attributed to equipment or system failure can also be rectified with $\mathrm{RCx}$.

d. An older building that has been inactivated and is being re-activated for continued use should be retro-commissioned as a part of the re-activation project unless the re-activation is for a short duration.

e. Recently completed projects between 1 - 3 years old will require follow-up to ensure that the building and systems are operating in an optimum manner, especially if the occupancy or use has changed somewhat from what was originally specified. Utilizing the RCx process in a newer building provides an opportunity to correct drift in controls, rectify changes in building system operation, and to repair equipment malfunctions. Moreover, $\mathrm{RCx}$ will identify changes in the function of the building and will implement corrections needed to meet the current requirements.

Note: It is a common misperception that new buildings operate efficiency and do not need the same attention that older facilities do. The reality is that most systems were not commissioned upon turnover, many systems were never checked for correct operation, and the building itself is more likely than not to be operating very inefficiently compared to its potential. The danger in leaving newer buildings alone, lies in the potential for increased energy waste and decreased productivity for many years until the building ages to where it is assumed that it needs attention.

A study of 60 newly constructed buildings revealed that:

- $50 \%$ suffered from control problems

- 40\% had HVAC equipment problems

- $15 \%$ had missing equipment

- 25\% had energy management systems, economizers, and/or variable speed drives that did not function correctly.

-- Lawrence Berkeley National Laboratory, 1996

f. Almost all normally occupied facilities will benefit from RCx. However, the more complex the building, the more important the RCx process becomes.

g. Select facilities to apply RCx by a formally developed set of criteria that is dependent upon the priorities and needs of the individual stakeholders. Use one of the following methods, or a combination thereof, for selecting facilities:

- Prioritize by the number of complaints received by the maintenance staff or the building manager. Facilities that are experiencing comfort problems, premature equipment deterioration, or have been historically problematic should be the first to apply retrocommissioning and will likely gain the most from the process.

- $\quad$ Prioritize by the magnitude of energy use. Group all facilities at the site by use-type and then calculate energy use per square foot $\left(\mathrm{Btu} / \mathrm{ft}^{2}\right)$. For example, of all similarly used 
laboratory facilities, one or two will stand out as being the heaviest energy consumer. Start the RCx process by applying it to these buildings first.

- Prioritize by maintenance costs. Group all facilities at the site by use type and then determine the total maintenance cost per square foot of each building. The facilities with the highest maintenance costs will likely be good candidates for RCx.

- Older buildings that have never received energy audits or upgrades may be good candidates for retro-commissioning. Older buildings generally have the least efficient equipment, the least amount of effective insulation, and are likely in the poorest condition. Older buildings generally have more to gain from the RCx process than do recently upgraded or properly operating newer buildings.

\section{A-6. Focus Area 3: Goals of the RCx Process}

a. Improve employee or tenant comfort, safety, and health, and improve the indoor environment through a systematic evaluation of building systems, equipment, and controls.

Note: The costs for employees and the processes being performed inside a building can significantly outweigh the costs of operating and maintaining the building.

b. Optimize energy efficiency through operation of the building as originally intended and through the identification and implementation of improvement upgrades.

c. Reduce operations, maintenance, and repair costs by implementing improvements to operational requirements and effective maintenance procedures.

d. Improve maintenance and operations personnel skills and awareness through training and certifications as necessary to maintain the building in an optimal operating condition and to implement a process for planned continuous re-commissioning

e. Gain acceptance of the retro-commissioning process as a standard and continuous operating method. Use project successes and maintenance staff expertise as leverage to implement a process for planned continuous re-commissioning of retro-commissioned facilities.

\section{A-7. Focus Area 4: Obtaining Management Support}

a. Without incentives for energy conservation, many building and organizational managers will not readily support $\mathrm{RCx}$ activities. Consider soliciting upper management organizations to add incentives for energy conservation/commissioning into the performance reviews of appropriate managers after upper management has embraced the concepts of $\mathrm{RCx}$ to leverage additional energy efficiency benefits.

b. Develop a strategic plan for incorporating RCx into the site's normal operations. Present this plan to management as a solution to rising utility costs and infrastructure issues. The strategic plan should include the benefits of RCx and the reason why the site should incorporate RCx.

c. Educate all management organizations concerned with buildings operations and maintenance on the value of $\mathrm{RCx}$, both in terms of avoided costs as well as increased productivity. 
d. Keep management regularly apprised of $\mathrm{RCx}$ project progress and accomplishments. Once regular meetings are anticipated, energy conservation measures and $\mathrm{RCx}$ issues can be freely discussed and acted upon.

e. Do not over-sell the benefits of RCx. Explain to stakeholders in, clear language, only the potential benefits that have a high probability of being achieved. Marginal benefits should not influence the decision to proceed with the $\mathrm{RCx}$ process. If an $\mathrm{RCx}$ project performs as, or better than, expected, the confidence level for the process and the potential for additional savings due to continued RCx will be enhanced.

\section{A-8. Focus Area 5: Setting Up the RCx Team}

a. The key to a successful retro-commissioning process is the commitment and professionalism of the $\mathrm{RCx}$ team. Communication among the team is paramount for uncovering building system problems and opportunities.

b. Organize a project team that is knowledgeable and capable of formulating and clearly defining the general building requirements and operational criteria. Selected team members must posses good communications skills and be able to work successfully in a team environment. Team members must be genuinely committed to energy conservation as well as to meeting stakeholder needs.

c. The RCx team should consist of representatives of various functional stakeholders. Team members should represent tenants, operations and maintenance personnel, and building owners as a minimum.

d. Suggested members for the RCx team include:

- Commissioning Authority

- $\quad$ Building Owner or Representative

- Project Manager

- Facility Energy Manager

- Mechanical, Electrical, and Controls Engineers

- Building or Tenant Manager or Representative

- Building Maintenance Representative

- Mechanical, Electrical, Controls, and Test and Balance Contractor Representatives

- Equipment Supplier / Vendor representative

e. Each team member has an equal voice and should be empowered to speak for his or her organization. The team members should also be able to communicate the requirements and needs of the RCx process back to their organizations.

f. The team should have a full understanding of the $\mathrm{RCx}$ process including the value of the team approach so they will be able to constructively provide input into the process. Training the team on the $\mathrm{RCx}$ process is primarily the responsibility of the Commissioning Authority.

g. The Commissioning Authority, in particular, must be intimately familiar with the RCx process and should coordinate and oversee all of the tasks in the RCx process. Being well-versed in sustainability concepts and the LEED ${ }^{\mathrm{TM}}$ Rating System would be of significant value to the 
Commissioning Authority. Overall, the Commissioning Authority is the primary contact and ultimate authority for all $\mathrm{RCx}$ issues.

\section{A-9. Focus Area 6: Performing the RCx Process}

a. Consider using the ESPC process to accomplish RCx. This method would be especially useful if the site does not have experience or expertise with energy audits, operational evaluations, condition assessments, or the commissioning process, or if funding for projects is difficult to obtain.

b. Ensure throughout the RCx process that clear, concise, and complete communications are maintained and insisted upon for all team members. The Commissioning Authority especially should ensure that all team members are kept up to date on all progress, completions, and issues of the RCx process. Good communication cannot be over-emphasized.

\section{c. Planning Phase}

- Determine the size and number of facilities that can be retro-commissioned with the available resources. Do not overestimate the amount of $\mathrm{RCx}$ that can be accomplished, especially the first time the process is used. Correctly performed $\mathrm{RCx}$, with its associated benefits, will help to secure the resources for continued RCx in additional facilities. Poorly executed RCx, on the other hand, will seriously jeopardize future opportunities to expand the RCx process.

- Document the known current building requirements, both operational and maintenance. These requirements will include those identified by both the tenant and owner. Documenting the building requirements will provide a guideline for determining correct building operation and will provide the basis for success.

- Use a series of meetings to solicit stakeholder input into how the building should operate, focusing on criteria such as building function, tenant comfort, energy use, maintenance, and current problems. Concerns and issues should be prioritized to ensure that the most important are addressed.

- Focus on current needs rather than existing problems. If the needs of the building are met, the problems will usually go away.

Note: It is good to document current problems, but the focus of the Planning Stage needs to be on the operational parameters needed for the building to be successful.

- Targeted systems for the RCx process should include building automation systems, HVAC systems, ventilation and fume hood systems, steam systems, chilled water systems, compressed air system, and lighting systems as a minimum.

Note: Remember to include all distribution piping and ductwork for leak testing when planning investigations.

- Establish detailed verification test procedures, functional test descriptions, and field test checklists for each targeted system.

- Prepare an execution document that will provide a roadmap of what will be accomplished by applying the $\mathrm{RCx}$ process. This document should include operating parameters, system configuration, an investigation plan, field check lists, worksheets, and other such documents as required to fully understand and document the current operation of the building. 
- $\quad$ Put resources in place to implement all low-cost and no-cost adjustments and modifications while the Investigation Phase is being performed.

\section{d. Investigation Phase}

- Gather and review design and as-built documentation, building and system drawings, system operational descriptions, system manuals, maintenance records, and Testing and Balancing reports to identify original operational parameters, system interaction, and construction quality issues.

- Perform system calibration, configuration, and performance field testing to identify actual sequences of operation, capacity, and other functional performance parameters to fully evaluate system performance.

Note: The Commissioning Authority should observe and verify most of the systems checks or the verification procedures at a minimum.

- Investigate system degradation, wear, and damage. Items of particular importance include boiler firing and operation, air system leaks, and electric motor condition and operation.

- Evaluate systems and components to determine if equipment is correctly sized, programmed, and operated to meet the current needs of the building or process.

- Document all findings whether positive or negative.

- Determine steps or tasks needed to correct problems with the building systems so that they can operate within the parameters as originally designed or as currently needed.

- Identify opportunities for operational enhancements and energy savings. Opportunities include no-cost adjustments and tuning, low-cost (under \$500) repairs and modifications, as well as higher cost long-term solutions to more complex problems.

\section{e. Implementation Phase}

Note: Strongly recommend the documentation of all control set-points, programming changes, and repairs affected, clearly indicating before and after conditions.

- Perform as many no-cost and low-cost adjustments or modifications as possible while implementing the Investigation Plan. Priority should always be given to the low and no-cost opportunities first.

- Submit recommendations for cost-effective capital improvement projects that will solve the complex problems identified during the Investigation Phase.

- Improvement recommendations should especially focus on the various building systems, operational issues, training opportunities, and documentation improvements that will help the building to operate within the current parameters identified during the planning phase.

Note: The building may be incapable of meeting current requirements if the needs of the building have significantly changed from its original mission. Significant upgrades may be required for the building to meet current requirements.. 
- Develop a plan to accomplish the recommendations. If a usable plan is not developed and pursued soon after the investigation phase has been completed, the recommended modifications may not be pursued and opportunities will be lost.

- Implement retesting of systems that are modified during the Implementation Phase or plan for retesting of systems that will be modified or upgraded at a later time. Remember that testing and verification are needed for successful completion of the RCx process.

- Update drawings or manuals as needed to ensure that operating parameters, system configurations, and any modifications are correctly documented for future reference and continued successful operation of the building.

- Determine updated maintenance practices that will eliminate or reduce the potential for reoccurrence of the identified system and equipment inefficiencies or failures.

\section{f. Hand-Off or Turnover Phase}

- Provide before and after documentation of all system field tests and equipment repairs or adjustments to the owner and maintenance organization.

- Provide copies of updated drawings or manuals and explain the changes that were made. Include the logic behind the change so that the operations and maintenance organizations can see the value of the change.

Note: Proper turnover of maintenance and operating data will enhance the organizations ability to continue to operate the building successfully.

- Consider providing video copies of tasks, steps, and key aspects of the RCx process when handing off to an owner or tenant that expects frequent turnover of maintenance or operations employees. The potential for frequent turnover and plans to provide records of the RCX process for future training should be identified in the planning phase.

\section{A-10. Focus Area 7: Maintaining the RCx Program}

a. Consider using the FEMP sponsored Continuous Commissioning Guidebook located at http://www.eere.energy.gov/femp/operations_maintenance/commissioning_guidebook.cfm.

b. Ensure that building operations and maintenance crews have a good understanding of the processes, methodology, and benefits of the commissioning process, which will help with the continuation of additional RCx projects.

c. Develop and maintain a master checklist of items to be included in a continuing RCx program. This should be a living document and should be an integral part of the operations and maintenance process and procedures.

d. Prepare a presentation for stakeholders outlining the commissioning process and the successes obtained to date. This presentation should include a plan for continued RCx projects and the benefits of adopting the plan.

Note: Remember that the quickest method for implementing ideas is to present a solution to an identified problem. 


\section{A-11. Focus Area 8: RCx References}

a. Reference Documents used to prepare the Guidance for Retro-commissioning:

Training Guide for The Commissioning Process for Retro-Commissioning Projects, Charles Dorgan, Program Director, Department of Engineering Professional Development, University of Wisconsin - Madison, January 27-28, 2005

Note: The Training Guide was used only for informational purposes. The University of Wisconsin - Madison, Department of Engineering Professional Development, has not endorsed this Best Practices document and has not collaborated with its development.

A Practical Guide for Commissioning Existing Buildings, Tudi Haasl, Portland Energy

Conservation, Inc., Terry Sharp, Oak Ridge National Laboratory, April 1999.

The Cost-Effectiveness of Commercial-Buildings Commissioning, Mills, Friedman, Powell, Bourassa, Claridge, Haasl, and Piette - Lawrence Berkeley National Laboratory, Portland Energy Conservation Inc., Energy Systems Laboratory: Texas A\&M University, December 15, 2004.

Departmental Energy and Utilities Management, DOE Order 430.2A, US Department of Energy, April 15, 2002.

FEMP Continuous Commissioning Guidebook for Federal Energy Mangers by Texas A\&M University, October 2002, available through http://ateam.lbl.gov/mv.

Building Commissioning Handbook, Heinz, John, P.E., APA Publications, Alexandrea, VA, 1996

b. Additional Informational References

ASHRAE Guideline 1-1996 - The HVAC Commissioning Process

ASHRAE Guideline 0-2005 - The Commissioning Process

The Building Commissioning Handbook, John A. Heinz and Richard B Casault, The Association of Higher Education Facilities Officers (APPA), 1996

Building Commissioning: The Key to Quality Assurance, USDOE Rebuild America / PECI, 1998

Building Commissioning Guidelines, Energy Design Resources, 2002, Available at: www.energydesignresources.com

Building Commissioning Association: http://www.bcxa.org

California Commissioning Collaborative: http://www.cacx.org

National Environmental Balancing Bureau (NEBB): http://www.nebb.org

Portland Energy Conservation, Inc. (PECI): http://www.peci.org

US Department of Energy / Federal Energy Management Program (FEMP):

http://www.eere.energy.gov/ 
National Institute of Building Sciences (NIBS) Total Building Commissioning:

http://sustainable.state.fl.us/fdi/edesign/resource/totalbcx/index.html

http://www.nibs.org/projwbdg.html

Many excellent presentations have been made at FEMP's Energy Conferences and the EFCOG Energy Efficiency Working Group (EEWG) meetings that would be helpful for developing RCx programs and preparing presentations to management. Refer to the following links for selected conferences and the EEWG:

http://www.eere.energy.gov/femp/energy_expo/2003/

http://www.eere.energy.gov/femp/energy expo/2004/

http://www.eere.energy.gov/femp/energy expo/2005/

http://www.efcog.org/wg/ee/index.htm 


\section{A-12. GLOSSARY}

As-Built Documentation- As-built documents include drawings and procedures that have been modified to reflect the actual equipment or system installation. As-built documents are not always available for many systems, but should be consulted when they are available as they are usually more accurate than the original drawings prepared as part of the design package. As-built drawings, or the lack of them, may provide clues to the incorrect operation or programming of building systems. As-built documents should always be prepared for any modifications that are made to a building as part of the commissioning process.

Commissioning - A process of ensuring that all building systems are installed and perform interactively according to the design intent, the systems are efficient and cost effective and meet the owner's operational needs, and the installation is adequately documented and that the operators are adequately trained.

Commissioning Authority - The individual hired by, or responsible to, the building owner and is tasked with implementing the commissioning process for a new or existing building. The Commissioning Authority is typically responsible for all aspects of the commissioning process, leads and trains the commissioning team, and witnesses or verifies all system checks or inspections throughout the process. The Commissioning Authority has final jurisdiction for the entire commissioning process.

Continuous Commissioning - Continuous commissioning involves ongoing monitoring and testing of systems as part of a regular maintenance plan to ensure optimum performance and enhanced equipment longevity. Continuous commissioning can be at a system or a building level depending upon the requirements of the stakeholders.

Energy Efficiency - The ability of a building to minimize the amount of energy used for employee safety, health, and comfort. Energy efficiency also applies to the processes that are performed inside the building, which are not necessarily part of the physical structure. Energy efficiency improvements should always be measured by life cycle cost effectiveness, and not by first cost or simple payback.

ESPC - Energy Savings Performance Contracts (ESPC) are projects that are developed, engineered, performed, and funded by an outside contractor called an Energy Services Contractor (ESCo).

ESPCs are paid for through the energy savings derived from the project and are intended to be a nocost turn-key process or project. The annual payments are made to the ESCo with funds that would have been distributed to the utility. ESPCs are especially useful when capital funding is not readily available. DOE sites can take advantage of the Super ESPC program which provides pre-evaluated ESCos familiar with Federal processes.

Field Testing - Field testing includes functional performance testing and inspections to equipment and systems during normal operating conditions to determine if they are calibrated, adjusted, and functional. Field testing verifies that components operate correctly, cycle at the right time, and are adjusted correctly. Many automated building control systems will indicate that components are correctly activated or accurately positioned, when they are, in reality, out of adjustment, damaged, or even completely inoperable. Field testing is paramount to a successful commissioning program.

$H V A C$ - Heating, ventilating, and/or air conditioning (cooling) systems in a building. HVAC systems include all components, controls, and distribution systems needed to deliver conditioned air to the desired point of use. 
Indoor Environment - A building's indoor environment includes many factors including the quality of the air in and supplied to the building, temperature levels and consistency throughout the building, amount of pollutants in the work space, lighting levels and quality, levels of unwanted sound, and amount of daylighting.

Leak Testing - A systematic method of evaluating air and steam systems for leaks. A formal planned testing method will provide the best returns for the investment.

LEED $^{\mathrm{TM}}$ Rating System - Leadership in Energy and Environmental Design (LEED) is a tool for green building design to help design team and owners determine green project goals, identify green design strategies, measure and monitor progress, and document success. The LEED ${ }^{\mathrm{TM}}$ Rating System was developed and is administered by the U.S. Green Building Council (USGBC), which is a national non-profit organization that includes representation from all aspects of the building industry. The LEED ${ }^{\mathrm{TM}}$ Rating System is a point system of five technical categories and four levels of certification: LEED Certified, Silver, Gold, and Platinum.

Low-Cost - Low Cost modifications or repairs may be performed during the commissioning process, but are typically implement shortly after. Low-cost opportunities typically cost less than $\$ 500$ and can be accomplished in bundled groups.

No-Cost-Adjustments or modifications that can be made during the commissioning implementation phase by in-house crafts. These on-the-spot modifications are essentially no-cost other than the time for the craft person to be available. No-cost adjustments should be maximized during the implementation phase.

Owner's Requirements - Functional and operational requirements that the owner specifies, which describe a properly operating building capable of meeting the mission or purpose of the building. The owner's requirements can be obtained solely from the building owner, or can preferably be a compilation of requirements by all building stakeholders obtained through a series of meetings to define and prioritize the requirements.

Re-commissioning - Commissioning that is performed several years after a building, which was previously commissioned, has been in operation to ensure that the building and systems are meeting the original design requirements. Re-commissioning is typically used to identify and correct malfunctions in a building that occur as the building ages and to ensure continued indoor air quality, employee productivity, and energy efficiency. Re-commissioning can also be used to address changes in ownership, building use patterns, and operation and maintenance practices. A building's use and mission often change during the building's life and these changes necessitate the need for re-commissioning to ensure that the building is capable of efficiently meeting its new and/or evolving mission.

Retro-commissioning - Applying the commissioning process to a building that has never been commissioned. Retro-commissioning is sometimes referred to as "Existing Building Commissioning" and is used to compare the building's original design parameters and operational criteria with current design and operational requirements. Retro-commissioning then determines if the building is capable of meeting its current mission needs and identifies modifications required to meet those needs. Retro-commissioning then identifies upgrades to the building that will enhance its energy efficiency, tenant comfort and productivity, and indoor air quality.

Retro-commissioning as a best Practice means using a whole building approach to ensure that the building is operating within well-defined criteria established by the building stakeholders. 
Stakeholders - Individuals or organizations that have an interest in the building, its mission, or the tenants that reside in the building. Stakeholders include the owner or owner's representative, operations personnel, maintenance organizations, production managers, facility engineers, and the Commissioning Authority.

Sustainability - The ability of a society to operate indefinitely into the future without depleting is resources. Sustainability includes concepts of green building design and construction, reuse and recycling of materials, reduced use of material and energy resources for building construction and operation, water conservation, and responsible stewardship of the environment adjacent to the building.

Testing and Balancing - Testing and Balancing (TAB) is a formal process of balancing the airflow of a building's HVAC system. The system is tested for required airflows, balanced to achieve the specified amount, retested for verification, and documented. Testing and Balancing is most often performed by an outside contractor that specializes in this service. 